\title{
Effect of sodium chloride on the growth parameters of canola plant (Brassica napus)
}

Kainat $^{1 *}$ and Muhammad Anwar Sajad ${ }^{1}$

1. Department of Botany, Islamia College Peshawar, KP-Pakistan

*Corresponding author's email: kainatalikhan98@gmail.com

Citation

Kainat and Muhammad Anwar Sajad. Effect of sodium chloride on the growth parameters of canola plant (Brassica napus). Pure and Applied Biology. Vol. 10, Issue 2, pp492-502.

http://dx.doi.org/10.19045/bspab.2021.100052

\begin{tabular}{llll}
\hline \hline Received: 02/07/2020 & Revised: 02/10/2020 & Accepted: 06/10/2020 & Online First: 27/10/2020 \\
\hline \hline
\end{tabular}

\section{Abstract}

Rapeseed (Brassica napus) is one of the most important plant producing essential oil. These oil are edible around the world. An experiment was carried out in triplicate in greenhouse condition at the botanical garden in Islamia College Peshawar. The experimental design consisted of four major groups which were arranged in sequences line and to study the effect of salinity stress on growth parameters, four level of salinity solution (0mM, 125mM, 250mM, 370mM) containing $\mathrm{NaCl}$ was applied in irrigation planting in a greenhouse. The results showed that salinity significantly affected the rate of germination, shoot length, leaves number, fresh weight of whole plant, fresh weight of root and number of flowers at $\mathrm{P}<0.05$. High concentration of $\mathrm{NaCl}$ significantly reduced the rate of germination, shoot length, leaves number, fresh weight of root and whole plant, as well as the number of flowers. It is necessary to indicate that canola plant cannot tolerate high concentrations of $\mathrm{NaCl}$ and damage under high salt stress condition. The highest value of growth parameters were observed under non-salinity condition (Control) with respect to salinity.

Keywords: Growth Parameters; NaCl; Rapeseed (Brassica napus); Salt; Stress

\section{Introduction}

Salinity is one of the most significant environmental factor which effect plant productivity extremely in arid and semi-arid climates [1]. Plants are uninterruptedly facing harsh environment, modulated by different environmental component, one is biotic factor such as parasites, pathogens, herbivores, etc. and second one is abiotic factor like nonliving matters such as salinity, drought, temperature, humidity, light, water, mineral nutrients, heavy metal and radiation etc [2]. Correspondingly to the USAD salinity laboratory, saline soil have high concentration of soluble salt. Ions donate soil salinity are $\mathrm{Na}^{+}, \mathrm{Cl}^{-}, \mathrm{Ca}^{++}$and $\mathrm{Mg}^{++}$[3]. Salts also obstruct with seed germination and crop establishment. Germination and seedling characteristics are the most achievable criteria used for selecting salt tolerance in plants. Salinity stress can influence seed germination through osmotic effects [4]. Canola (Brassica napus L.) plant can grow under different environmental conditions especially under the drought, salinity and temperature stresses [5]. Salt-affected lands transpired in virtually all climatic regions, from the humid tropics to the Polar Regions. 
All soils consist salts and all irrigation waters, from canal pumping, carry some dissolved salt which are necessary elements of soil (nitrates and potassium). Precisely, about $2 \%$ of the lands farmed by dry-land agriculture, Mediterranean regions are directly undergo enlarged salt stress issues developed from seawater entrance into aquifers and irrigation with brackish water [6]. Primary salinity results from the agglomeration of salts over long periods of time through natural processes in the groundwater. It is created by two natural action. The first action is the weathering action which break down rocks and release soluble salts of different types mainly chlorides of $\mathrm{Na}, \mathrm{Ca}$, and $\mathrm{Mg}$, and to a lesser extent, sulfates and carbonates. The second action is the deposition of oceanic salt carried by wind and rain [7]. Two basic stresses influence plants under salinity are osmotic and ionic stresses. Osmotic stress occurring immediately in the root medium on exposure to salts can result in inhibition of water uptake, cell expansion and lateral bud development. Ionic stress develops when toxic ions like $\mathrm{Na}^{+}$accumulate in cells causing increase in leaf mortality, chlorosis, necrosis and decrease in the activity of cellular metabolism including photosynthesis. In fact excess of $\mathrm{Na}^{+}$and $\mathrm{Cl}^{-}$ have the potential to destroy plant enzymes, refuse energy construction and other physiological processes. Salt stress impact growth and development of plant; yet, the feedback of plants is different with the state of stress and crop growth stage. Seed germination is the most introductory time in seedling establishment. Germination and early seedling growth are additionally sensitive to salinity than later developmental stage. Hyper-osmotic stress and toxic outcomes of sodium and chloride ions on germinating seeds in a saline soil may inhibit germination. It has been reported that salinity adversely affect the process of germination in different plants like Posidonia, Oryza sativa, Triticum aestivum, Zea mays and Brassica. In Brassica napus the rate of germination is reduced with increase in the salt concentration. Photosynthesis is one of the most fundamental biochemical pathway by which solar energy is convert into chemical energy in the form of sugar. Photosynthesis rate decreases due to salt stress, more salt are responsible to reduce the osmotic potential, accumulation of $\mathrm{Na}$ and $\mathrm{Cl}$ ions in the chlorophyll, so in this way the photosynthesis rate is reduced. Moreover literature exhibited that the $O$. sativa leaves decline the chlorophyll a and $b$ content of the leaves after the treatment of $\mathrm{NaCl}$. It is observed that the chlorophyll b was effected $41 \%$ and chlorophyll a was effected 33\% [8, 9]. According to the theory Gouy-Chapman, it was concluded that $\mathrm{Na}$ : $\mathrm{Ca}$ interaction construct at the plane of the membrane. $\mathrm{NaCl}$ salinity decreases the surface potential of the plasma membrane, surface charge density and ions activity, reduction in the surface charge density of the membrane, reduce the cation activity at the outside surface of the membrane as result the ions transport across the plasma membrane are effected [10]. Salinity cause the nutrient imbalances, due to the competition of the $\mathrm{Na}^{+}$and $\mathrm{Cl}^{-}$with other plant nutrient such as $\mathrm{K}^{+}, \mathrm{Ca}^{2+}$ and $\mathrm{NO}^{3-}$. The saline soil decreased the plant growth because of ion toxicities $\left(\mathrm{Na}^{+}\right.$and $\left.\mathrm{Cl}^{-}\right)$. $\mathrm{NaCl}$ interaction increase with other element and decreased the amount of $\mathrm{K}, \mathrm{P}, \mathrm{Ca}, \mathrm{N}$ and $\mathrm{Mg}$ [11]. Canola (Brassica napus L.) belong to the genus Brassica and family Brassicaceae. It is also called rapeseed and is widely cultivated plant around the world for the production of edible oil and biodiesel fuel. It is third most important crop plant after soybean and palm. The canola yield is reduced due to the salt stress. Several articles have been written about the canola plant morphological, physiological and biochemical response to salt stress [12]. 
Current research work was conducted on the effects of the salt stress on the growth parameters of the canola plant.

\section{Materials and methods}

\section{Selection of plant}

The selected plant for the research was canola (Brassica napus), belong to the genus of Brassica and the family of Brassicaceae. Canola is commonly called rapeseed and oilseed. Rape is a word derived from Latin rapum meaning turnip. Generally it is used as edible oil. From the germination to seed production, the life cycle of canola plant is completed in $3 \frac{1}{2}$ months, based on temperature, moisture, sunlight and soil fertility.

\section{Collection of seed}

The canola seeds (Husnain variety) were obtained from the Turnab, Agriculture University Peshawar. The seeds were same size and color. 84 seeds were used in the research.

\section{Experimental design}

A total of 12 pots were used in the experiment. The experiment was conducted in triplicate in the greenhouse condition at the botanical garden in Islamia College Peshawar. The experimental design consisted of four major groups which were arranged in sequences line. The main groups were Control group, Experiment 1, Experiment 2 and Experiment 3. Seven seeds were sown in each pot of each one group.

Concentration of salt $(\mathrm{NaCl})$ used in experiment

Different concentration of sodium chloride $(\mathrm{NaCl})$ were used in the experimental groups. No salt was added to the control group while $125 \mathrm{mM}, 250 \mathrm{mM}$ and $370 \mathrm{mM} \mathrm{NaCl}$ was added in solution form to the each one pot of rest of the group's i.e. Experiment 1, Experiment 2 and Experiment 3 respectively. The three concentration of the salt was prepared using the following formula, 1Molar solution of $\mathrm{NaCl}=1000 \mathrm{mM}$ solution of $\mathrm{NaCl}=58.5 \mathrm{~g} \mathrm{NaCl} / 1000 \mathrm{ml}$

\section{Procedure}

For $125 \mathrm{mM}$ solution, $3.65 \mathrm{~g}$ of sodium chloride was dissolved in $1000 \mathrm{ml}$ of distilled water while for $250 \mathrm{mM}$ solution, $7.31 \mathrm{~g}$ of sodium chloride was dissolved in $1000 \mathrm{ml}$ of distilled water. For $370 \mathrm{mM}$ solution, $10.96 \mathrm{~g}$ of sodium chloride was dissolved in $1000 \mathrm{ml}$ of distilled water.

\section{Effects of $\mathrm{NaCl}$ on the germinations}

The seeds of canola plant were grown on 2 Nov, 2019 and give solutions of $\mathrm{NaCl}$ to the experimental groups. First I visited after 9 days to the field and observed that the seed has started germination. The effects of the used salts on the germination of the canola seeds were recorded by counting the number of germinated seeds in each pot. By this way I visited to the field after every three days and after nine days I recorded the data by the same method.

\section{Effects of $\mathrm{NaCl}$ on the shoot length}

The shoot of both control and those which were treated with different concentrations of sodium chloride was measured with the help of ruler in centimeter. The shoot length was considered from the soil of the pot to the apex of the plant.

\section{Effects of $\mathrm{NaCl}$ on Fresh and dry weight}

When the plants were fully matured, they were harvested and the fresh weight of the plants was determine in gram $(\mathrm{g})$ using digital balance.

\section{Effects of $\mathrm{NaCl}$ on the root weight and number of leaves}

When experimental plants were harvested from the pots after maturity. Then they were separated into parts (shoots and roots). The root weight was taken in gram (g) using digital balance. The number of leaves were counted in the plants grown in control group and those which were treated with different concentration.

\section{Results}

The experiment was carried out in the Botanical Garden Department of Botany Islamia College, Peshawar to find out the 
effect of sodium chloride on the various growth parameter of canola plant (Brassica napus). The experimental period continued for about 30 days from seed sowing up to the maturity of the plants. During this period data regarding germination and growth were recorded. The main growth parameters of the selected plant in relation of the effects of salinity studied in the course of this research work are;

\section{Effects of $\mathrm{NaCl}$ on germination}

The effects of the used three different concentration of $\mathrm{NaCl}(125 \mathrm{mM}, 250 \mathrm{mM}$, and $370 \mathrm{mM}$ ) on the rate of germination was determined. After seed sowing and addition of different concentration of $\mathrm{NaCl}$ to the respective pots for a few days, the germination and seedling growth appeared differently in control and in those which were treated with different concentration of sodium chlorides $(\mathrm{NaCl})$ as shown in the (Fig. 1). Error bars shows standard deviation which were found statistically significant. The maximum reduction in germination was observed at a high concentration of sodium chloride in soil (Exp3) followed by (Exp2) while low concentration (Exp1) of $\mathrm{NaCl}$ in soil increased the rate of germination slightly with respect to without treated soil (Control group). Overall statistically significant difference was found in the rate of germination in the seeds grown in control and experimental groups using one way anova (at $\mathrm{P}<0.05$ and $\mathrm{P}$ value summary of $* * * *$ )

\section{Effects of $\mathrm{NaCl}$ on the shoot length}

At the time of harvesting, selected seven plants from each pot. The shoot elongation was measured in centimeter at top of shoot from the base with the help of digital ruler. The shoot length of both control group and which were treated with different concentration of sodium chlorides was measured as shown in (Fig. 2). Error bar shows standard deviation which were found statistically significant. The maximum declination in shoot elongation was observed at high concentration of sodium chloride (Exp3) followed by (Exp1) while to a small extent (Exp2) of sodium chloride promoted the shoot elongation with respect to untreated group (control). It means that low concentration of sodium chloride is beneficial for shoot elongation. Overall statistically significant difference was found in shoot elongation in control and experimental groups using one way anova (at $\mathrm{P}<0.05$ and $\mathrm{P}$ value summary of $* * * *)$.

\section{Effects of $\mathrm{NaCl}$ on number of leaves}

The matured plants after completing their life cycle were harvested from groups of each pot and counted the number of leave of Brassica napus of every plant. Observed different data regarding the number of leaves in treated and untreated groups as shown in (Fig. 3). Standard deviations were found statistically significant. Maximum reduction in the leaves number in plants was observed at high concentration of sodium chloride in the soil (Exp3) followed by (Exp2) and (Exp1) while a maximum number of leave was found in untreated soil (control group) with respect to experimental groups. It indicates that salinity is responsible for reduction in the leaves number. Overall statistically significant difference was found in the number of leaves in the seed grown in control and experimental groups using one way anova (at $\mathrm{P}<0.05$ and $\mathrm{P}$ value summary of $* * * *)$.

\section{Effect of $\mathrm{NaCl}$ on the fresh weight of the plant}

After plant harvesting, directly determined the fresh weight with the help of digital balance. Measured the fresh weight of all groups (control and treated) of all parts of the plant canola (shoot and root system) in gram as shown in (Fig. 4). Standard deviations were found statistically significant. Maximum reduction in fresh weight was observed at high concentration of sodium chloride in soil (Exp3) followed by (Exp1) and then (Exp2). While plant grown in nonsaline soil (control group) exhibit high fresh 
weight with respect to experimental groups. Statistically significant difference was found in the fresh weight in seed grown in control and experimental groups (at $\mathrm{P}<0.05$ and $\mathrm{P}$ value summary of $* * * *)$.

Effect of $\mathrm{NaCl}$ on the initiation and maturation of flowering

At the start of the flowering period up to maturity flowers were counted in plants in treated and untreated groups. Data of initiation of flowers were collected in five days interval. After ten days the collected data is shown in (Fig. 5a). Error bars shows standard deviation which were found statistically significant. The maximum reduction in the initial of flowering was observed at a high concentration of sodium chloride in soil (Exp3) followed by (Exp2) and (Exp1). While maximum flowers were found in non-salinity (control group) with respect to salinity in soil (Experimental groups). Statistically significant difference was found in control and experimental groups using one way anova (at $\mathrm{P}<0.05$ and $\mathrm{P}$ value summary of $* *)$. After the maturation period of the plant, counted the number of flower as shown in (Fig. 5b). Error bars shows standard deviation which were found statistically significant. The maximum reduction in number of maturation of flowers was observed at high concentration of sodium chloride in soil (Exp3) followed by (Exp2) and (Exp1). While maximum number of maturation of flowers in non-salinity (control group) with respect to salinity (Experimental groups) in soil. Overall statistically significant difference was found in control and experimental groups (at $\mathrm{P}<$ 0.05 and $\mathrm{P}$ value summary of $* * * *)$.

\section{Effect of sodium chloride on the fresh weight of root}

The plants were matured after completing the life cycle and then plants were harvested from groups of each pots and determine fresh weight of the root of plant by digital balance. Fresh weight data of the root grown in salinity and non-salinity conditions is shown in (Fig. 6). Error bars shows standard deviation which were found statistically significant. The maximum reduction in fresh weight of root was observed at highest concentration of sodium chloride (Exp3) followed by (Exp1) while to a small extent of sodium chloride concentration increased the fresh weight slightly with respect to nonsalinity (control) in soil. Overall statistically significant difference was found in nonsalinity (control group) and salinity (Experimental groups) $(\mathrm{P}<0.05$ and $\mathrm{P}$ value summary of $* *)$.

\section{Discussion}

The effects of sodium chloride $(\mathrm{NaCl})$ on the rate of germination of the selected plant is clear from (Fig. 1). Results showed that an increase in the concentration of sodium chloride $(\mathrm{NaCl})$ decreased the rate of germination but to a smaller extent increase in the concentration of the same salt increased the rate of germination. It demonstrated that an increase in soil salinity decreases the rate of germination. Our findings are similar to the results of [1-13]. Similar research work was conducted and found significant maximum reduction in germination at high concentration of sodium chloride. Findings of the current research work regarding the effects of $\mathrm{NaCl}$ on germination are in agreement of the findings of [13]. Our finding are similar to the result of [14-16] indicated that the different treatments of salinity stress considerably effected the rate of germination.

The effect of sodium chloride $(\mathrm{NaCl})$ on the shoot elongation is shown in (Fig. 2). Results showed that increase in level of sodium chloride $(\mathrm{NaCl})$ declined the shoot elongation (Exp3) while low concentration of sodium chloride increased the shoot length (Exp2). It is reported that salt stress affect the plant growth, and declined the shoot elongation. Our findings are similar to the results of [17]. Similar research work was conducted and 
found significant maximum reduction in shoot elongation of pepper seedling at high level of sodium chloride. Finding of current research regarding the effects of $\mathrm{NaCl}$ on shoot elongation are in agreement of the findings of [18]. Similar research work was conducted by [19] and exhibited that reduction in shoot length was found at high concentration of $\mathrm{NaCl}$ with respect to nonsalinity.

The effect of sodium chloride on the leaves number is shown in (Fig. 3). Results shows that high concentration of $\mathrm{NaCl}$ caused significant reduction in leaves number. Similar research work was conducted by [20]. The micro shoot was exposed to salinity. Slight reduction was obtained in leaves and shoot number.

The effect of salt of $\mathrm{NaCl}$ on the fresh weight of plant of canola is shown in (Fig. 4). Results showed that increased in concentration of $\mathrm{NaCl}$ (Exp3) reduced the fresh weight of rapeseed. It is demonstrated that salt stress caused a significant reduction in length, wet (fresh) and dry weight. Our findings are similar to the results of [21]. Similar research was conducted by [22] and showed that salt stress inhibited plant growth (shoot length, fresh root and shoot weight but root growth was more effected than shoot).

The effect of sodium chloride stress on flowers is shown in (Fig. 5a, b) Results showed that increased in concentration of $\mathrm{NaCl}$ caused a significant reduction in flowers of rapeseed. It is indicated that increased in salinity $(\mathrm{NaCl})$ cause reduction in number of branches per plant, flowers per plant, and also significantly reduced the fresh and dry flowers weight. Our finding are similar to the results of [23].

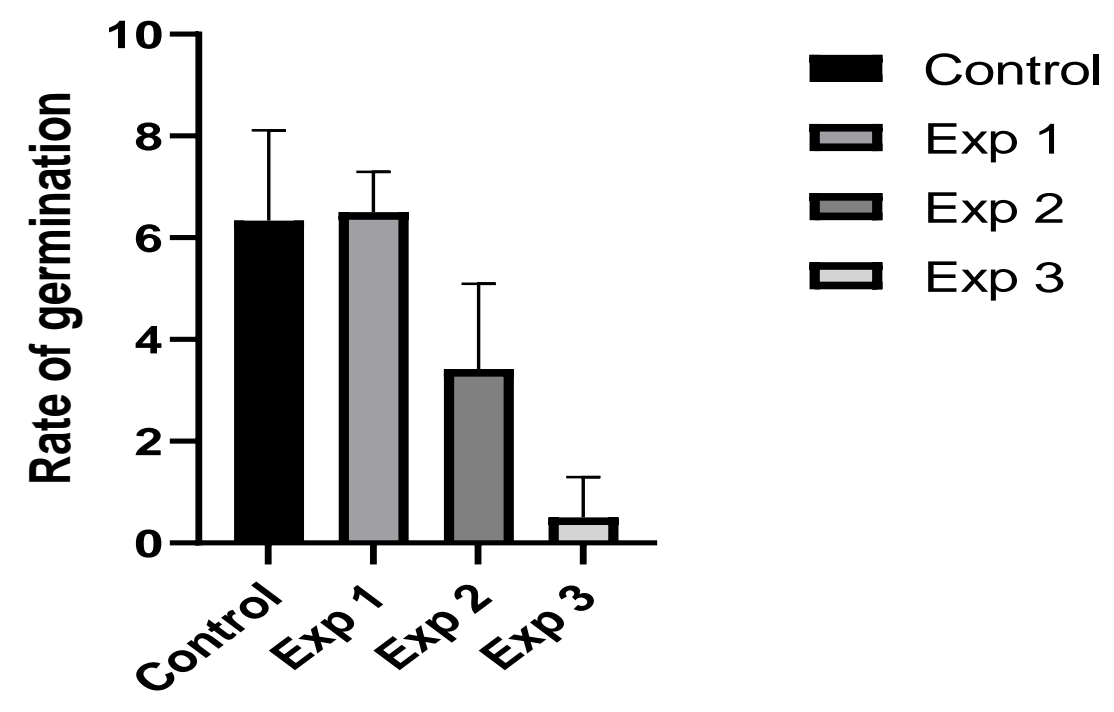

Growth of canola plant in control and $\mathrm{NaCl}$ treated soil

Figure 1. Effect of different concentration of $\mathrm{NaCl}$ on seed germination of Brassica napus 


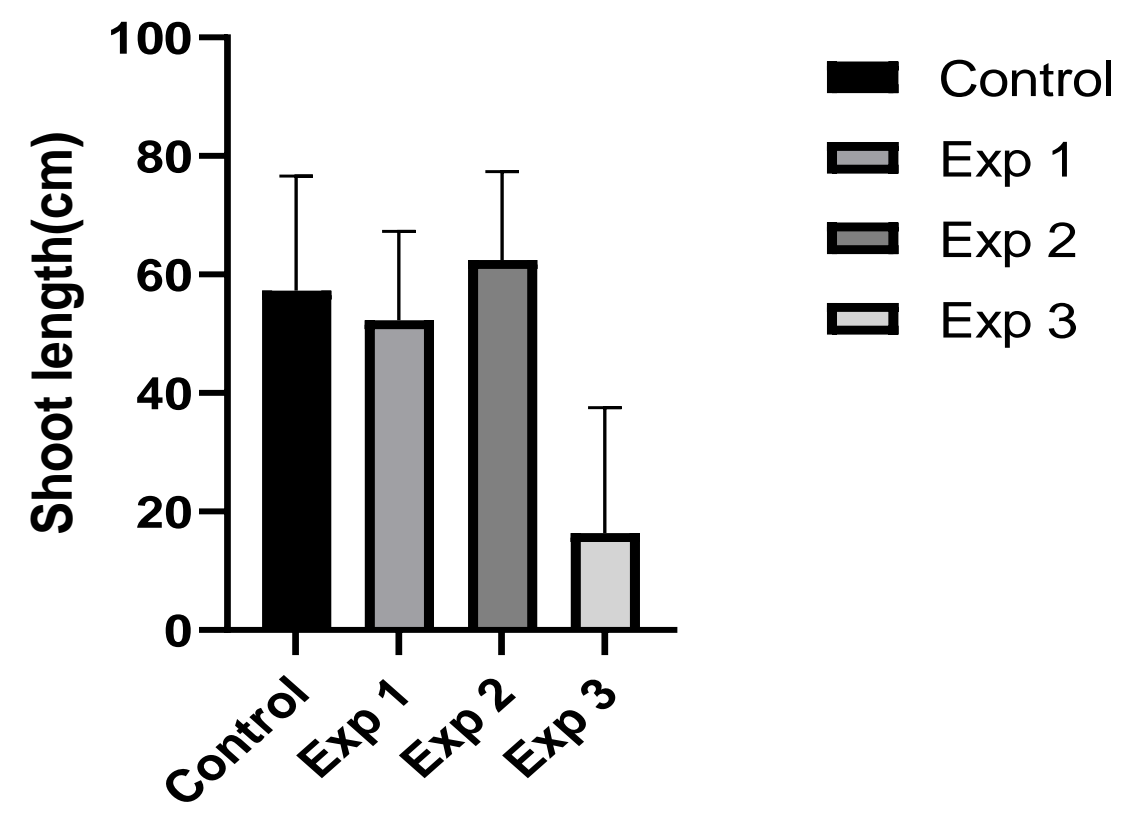

Growth of canola plant in control and $\mathrm{NaCl}$ treated soil

Figure 2. Effect of different concentration of $\mathrm{NaCl}$ stress on the shoot length of Brassica napus

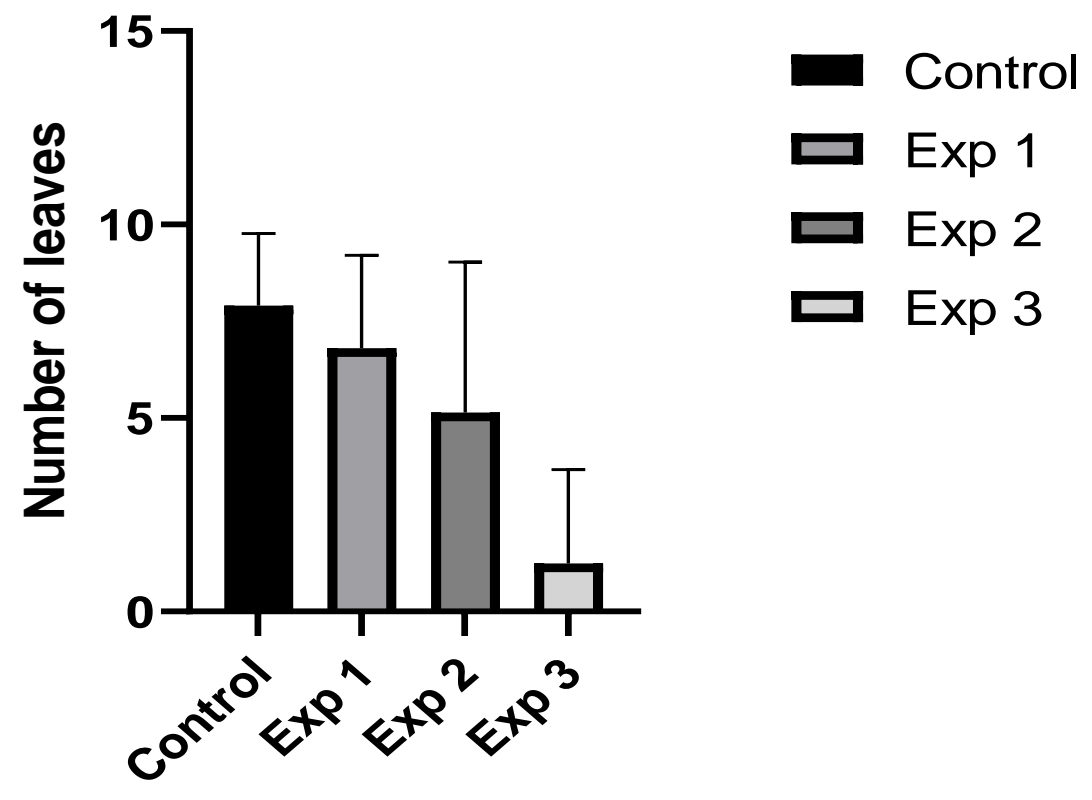

Growth of canola plant in control and $\mathrm{NaCl}$ treated soil

Figure 3. Effect of different concentration of $\mathrm{NaCl}$ on number of leave of Brassica napus 


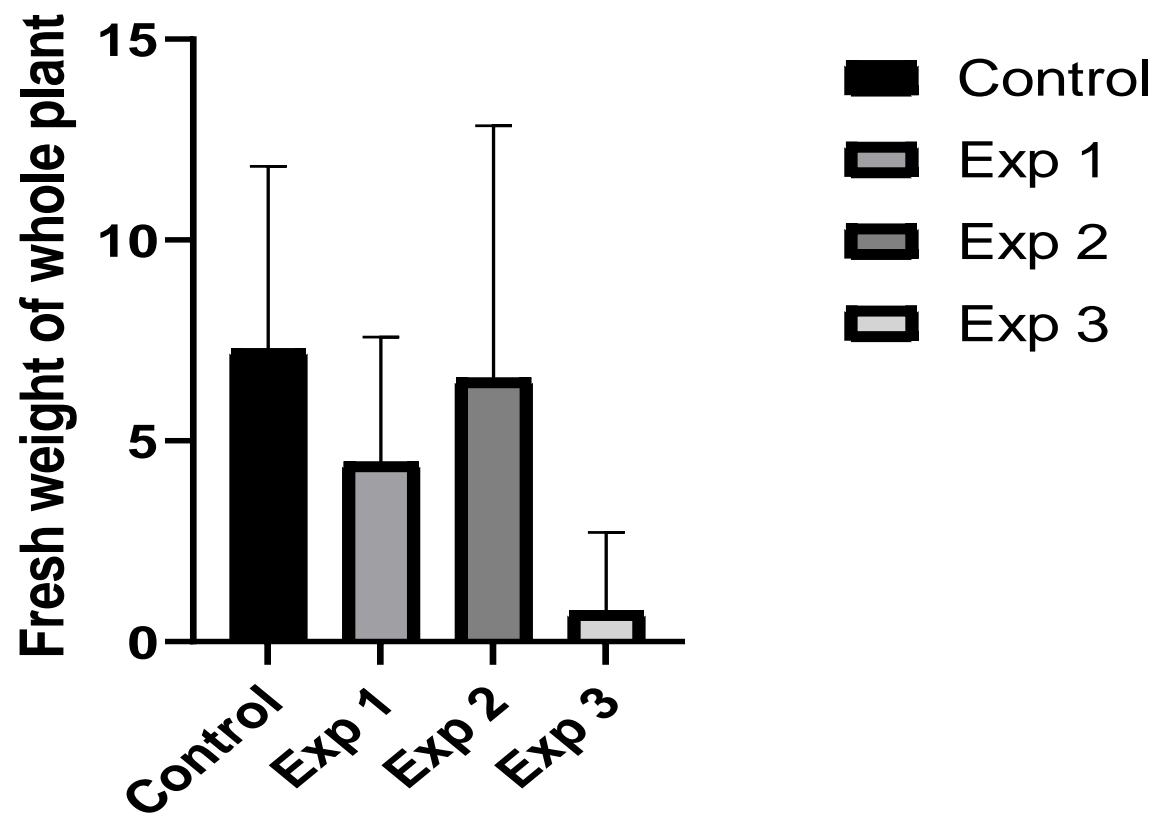

\section{Growth of canola plant in control and $\mathrm{NaCl}$ treated soil}

Figure 4. Effect of different concentration of $\mathrm{NaCl}$ stress on the fresh weight of Brassica napus

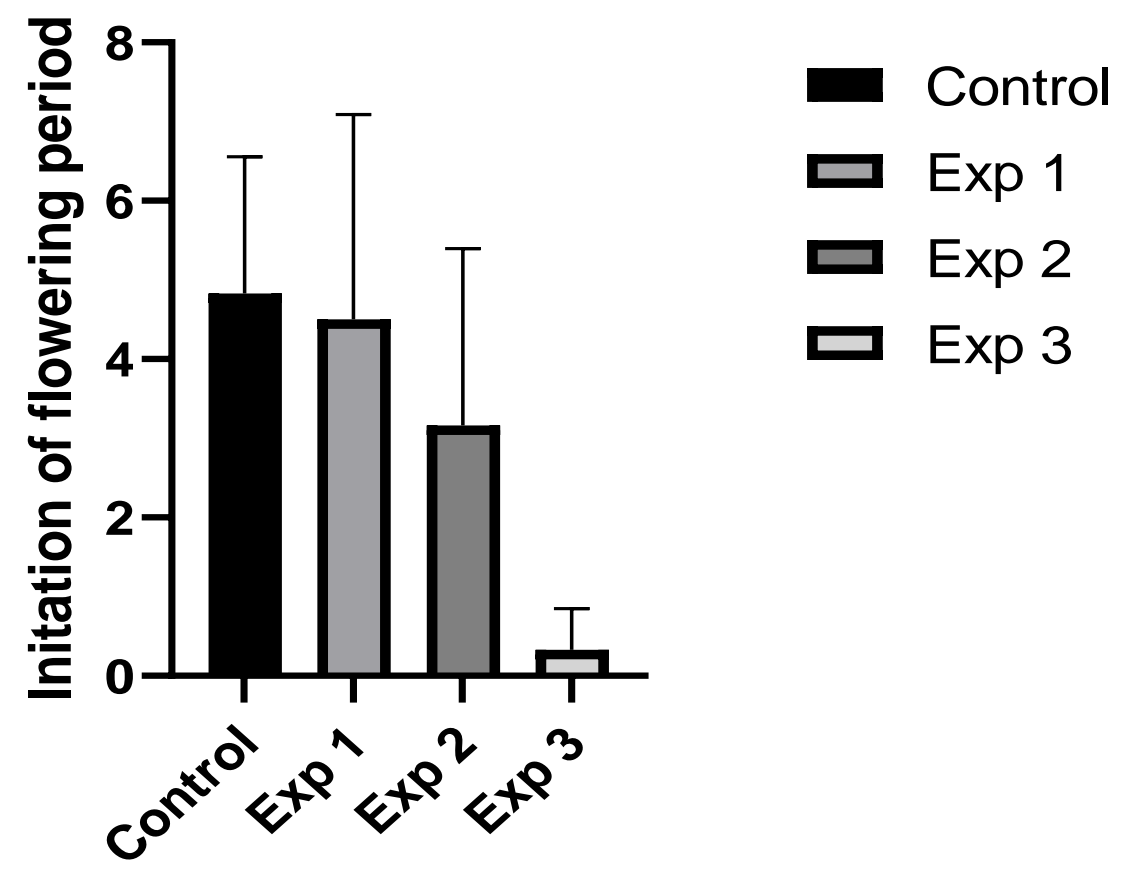

Growth of canola plant in control and $\mathrm{NaCl}$ treated soil

Figure 5(a). Effect of different concentration of $\mathrm{NaCl}$ stress on the initiation of flowering of Brassica napus 


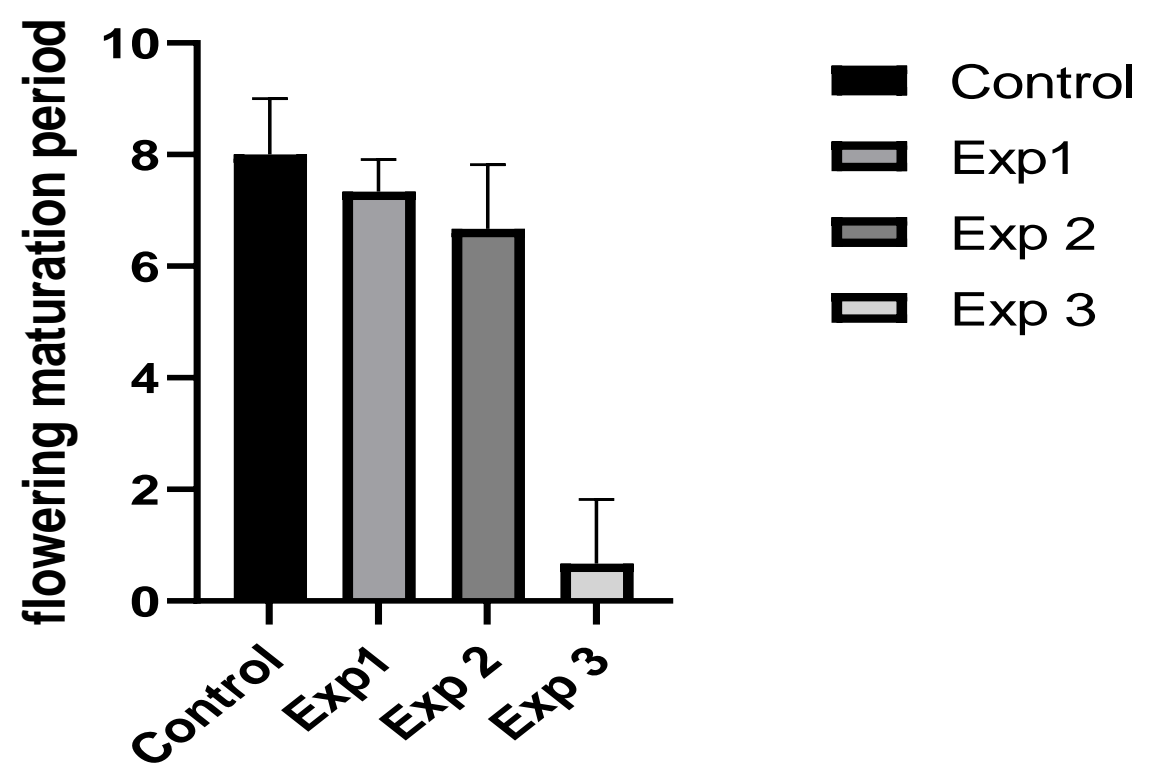

Growth of canola plant in control and $\mathrm{NaCl}$ treated soil

Figure 5(b). Effect of different concentration of $\mathrm{NaCl}$ on the maturation of flowering of Bassica napus

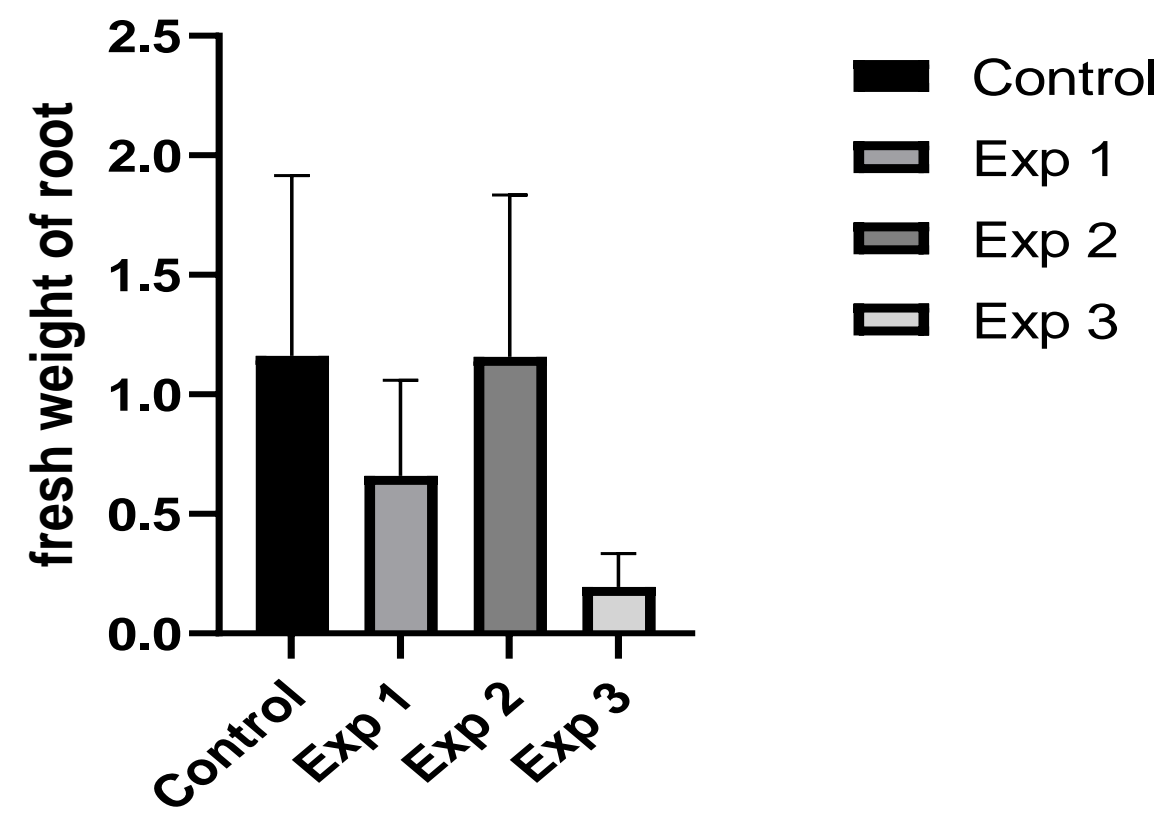

Growth of canola plant in control and $\mathrm{NaCl}$ treated soil

Figure 6. Effect of different concentration of $\mathrm{NaCl}$ on the fresh weight root of Brassica napus 


\section{Conclusion}

Based on current research work it is concluded that the rate of germination, shoot length, leaves number, fresh and dry weight of plant and root were negatively effected at a high concentration of sodium chloride stress as compare to the plants grown in non saline soil. However low concentration of sodium choride was found to increse the rate of germination with repect to non-salinity.

\section{Authors' contributions}

Conceived and designed the experiments: MA Sajad, Performed the experiments: Kainat, Analyzed the data: Kainat, Contributed materials/ analysis/ tools: Kainat Wrote the paper: Kainat, MA Sajad.

\section{Acknowledgements}

This work was supported by my respected supervisor Dr. Muhammad Anwar Sajad and my brother Muhammad Haroon.

\section{References}

1. Acosta-Motos JR, Ortuno MF, BernalVicente A, Diaz-Vivancos P, SanchezBlanco MJ \& Hernandez JA (2017). Plant Responses to Salt Stress: Adaptive Mechanisms. Agron 7(18): 2-43.

2. Singh M, Kumar J, Singh S, Singh VP \& Prasad SM (2015). Roles of osmoprotectants in improving salinity and drought tolerance in plants. Rev in Environ Sci and Biotechnol 14(3): 407426.

3. Mudgal V, Madaan N \& Mudgal A (2010). Biochemical Mechanisms of Salt Tolerance in plant. Inter $J$ of Bot 6(2): 136-143.

4. Jamil M, Lee DB, Jung KY, Ashraf M, Lee SC \& Rha ES (2006). Effect of salt $(\mathrm{NaCl})$ Stress on Germination and early seedling growth of four vegetables species. J Central Euro Agric 7(2): 273282.

5. Toorchi M, Naderi R, Kanbar A \& Shakilba RM (2011). Response of spring canola cultivars to sodium chloride stress. Ann of Biol Res 2(5): 312-322.
6. Carillo P, Annunziata MG, Pontecorvo G, Amodio F \& Woodrow P (2010). Salinity stress and salt tolerance. Abiotic Stress in Plant-Mechanisms and Adap 1: 21-38.

7. Parihar P, Singh S, Singh R, Singh VP \& Prasad SM (2014). Effect of salinity stress on plants and its tolerance strategies. Environ Sci and Poll Res 22(6): 4056-4075.

8. Panuccio MR, Jacobsen SE, Akhter SS \& Muscolo A (2014). Effect of saline water on seed germination and early seedling growth of the halophyte quinoa AoB Plants 6.

9. Farooq M, Hussain M, Wakeel A \& Siddique KHM (2015). Salt stress in maize: effects, resistance mechanisms, and management Dptt of Agron 35: 461481.

10. Cramer GR (2002). Sodium-calcium interaction under salinity stress. Deptt of Biochem 205-227.

11. Jouyban Z (2012). The Effects of Salt stress on plant growth. Tech $J$ of Engineer and Appl Sci 2(1): 7-10.

12. Gharelo RS \& Noparvar PM (2018). Molecular response of canola to salt stress: insights on tolerance mechanisms. Peer J 6: e4822.

13. Petrovic G, Jovicic D, Nikolic Z, Tamindzis G, Ignjatov M, Milosevic D \& Milosevic B (2016). Comparative study of drought and salt stress effects on germination and seedling growth of pea: Genetika 48(1): 373-381.

14. Jamil M, Lee CC, Rehman SU, Lee DB, Ashraf M \& Rha ES (2005). Salinity $(\mathrm{NaCl})$ tolerance of Brassica species at germination and early seedling growth. Electron J Environ Agric Food Chem 4: 970-976.

15. Farhoudi R \& Sharifzadeh F (2006). The effects of $\mathrm{NaCl}$ priming on salt tolerance in canola (Brassica napus L.) seedlings 
grown under saline conditions. Indian $J$ of Crop Sci 1: 74-78.

16. Miyamoto S, Foster M, Trostle C \& Glenn E (2012). Salt tolerance of oilseed crops during establishment. J of Arid Land Stud 22(1):147-151.

17. Shahid MA, Pervez MA, Balal RM, Ahmad R, Ayyub CM, Abass T \& Akhter N (2011). Salt stress effect on some morphological and physiological characteristics of okra. Soil Environ 30(1): 66-73.

18. Yilmaz K, Akinci IE \& Akinic S (2004). Effect of salt stress on the growth and $\mathrm{Na}, \mathrm{K}$ contents of peper (Capsicum annuиm L.) in germination and seedling stage. Pak J of Biol Sci 7(4): 606-610.

19. Husssanein RA, Bassuony FM, Baraka DM \& Khalil RR (2009). Physiological effect of Nicotinamide and Ascrobic acid on the Zea mays plant grown under salinity stress. I-changes in growth, some relevant metabolic activities and oxidative defense system. Res of $J$ of
Agric and Bilogical Sci 5(1): 72-81.

20. Shiyab SM, Shibli RA \& Mohammad MM (2003). Influence of Sodium Chloride Salt Stress on Growth and Nutrient Acquisition of Sour Orange in Vitro. J of Plant Nutr 26(5): 985-996.

21. Bandeoglu E, Eyidogan F, Yucel M \& Oktem HA (2004). Antioxidant responses of shoots and roots of lentil to $\mathrm{NaCl}$-salinity stress. Plant Growth Reg 42: 69-77.

22. Janmohammad M, Abbasis A \& Sabaghnia N (2012). Influence of $\mathrm{NaCl}$ treatments on growth and biochemical parameters of castor bean (Ricinus communis L.). Acta Agricalturae Slovenica 99(1): 31.

23. Razmjoo K, Heydarizadeh $\mathrm{P}$ \& Sabzalian MR (2008). Effect of Salinity and Drought Stresses on Growth Parameters and Essential Oil Content of Matricaria chamomile. Inter J of Agric and Biol 10(4): 451-4. 